\title{
Challenges and Opportunities in Climate Economics
}

\author{
Sunbin Yoo, Junya Kumagai and Shunsuke Managi* \\ Urban Institute, Kyushu University, Fukuoka, Japan
}

Keywords: climate economics, climate change, social costs of carbon, uncertainty-identity, economic model

\section{IMPORTANCE OF UNDERSTANDING CLIMATE ECONOMICS}

We are living in an era in which the average person emits $\sim 5$ tons of carbon dioxide (hereafter referred to as $\mathrm{CO}_{2}$ ) emissions each year (Le Quéré et al., 2018). $\mathrm{CO}_{2}$ emissions, along with other greenhouse gases, distort the planet's energy balance and result in climate change, which has a wide range of causes and impacts, and those in low-income countries who contribute the least to climate change are the most vulnerable to its effects (Tol, 2009; Partridge et al., 2017). Climate change also poses another long-term problem because some greenhouse gases have tens of thousands of years of atmospheric life, and a quarter of the emissions remaining in the atmosphere for over a millennium (Archer et al., 2009). Numerous researches attempt to understand climate change in a field of natural science have been already done, however, the key questions or measurements about the consequences of climate change that are "economically" or "socially" crucial remain unanswered (Hsiang and Kopp, 2018). Hence, starting from Nordhaus (1977), researchers seek to understand climate change from economic and social perspectives and provide policy options that can mitigate/adapt the consequences of climate change. To this end, climate economics starts to rise as it allows us to understand climate change and provide solutions to combat it through toolkits that incorporate various economic theories and empirical models to reflect people and the economy.

Climate economics covers a broad range of topics. In classical economic theory, climate economics includes optimal natural resources extraction, which is known as Hoteling's rule, and optimal tax policies known as Pigouvian tax. Recently, Climate economics started to cover the urge to reduce greenhouse gases and mitigate climate change as the harms of climate change would dominate the world (Tol, 2014). These lists of topics have already been highlighted from the past. Still, it has increasingly become essential with current global environmental problems: increasing $\mathrm{CO}_{2}$ emissions, rising sea levels, and health impacts of climate change that start to emerge and threaten the people and the economy. The broadness of climate change requires climate economics to provide solutions that can encompass these various aspects.

To do so, climate economics requires global and interdisciplinary efforts because climate change hazards incorporate various aspects, including technology (Karakosta et al., 2010; Gans, 2012), health (Deschênes et al., 2009; Jones, 2019; Barreca and Schaller, 2020), well-being (Kelly and Adger, 2000; Barnett, 2003; Pecl et al., 2017), and energy (Karl and Trenberth, 2003; Davis et al., 2010; Spence et al., 2011). Thus, reaching out to other disciplines and finding a balance between disciplinary excellence and interdisciplinary collaboration is crucial for climate economics. Additionally, given that the new topics frequently emerge in climate economics thanks to technological innovations, globalization, new political agendas, and new social/environmental problems, identifying the key challenges and opportunities would contribute when the new challenge comes.

In this paper, therefore, we identify the two main challenges of climate economics and opportunities for them. To do so, we review recent journal articles which cover two crucial topics that incorporate challenges and opportunities in climate economics: Measurement of intangible assets and estimating the social cost of carbon (SCC). While both issues are representative topics in 
climate economics, both in topical and methodological aspects, there are still challenges therefore overcoming such challenges would provide opportunities to tackle climate change. Overcoming the challenges would allow climate economics to reach interdisciplinary and global solutions.

\section{MEASURING INTANGIBLE CONSEQUENCES OF CLIMATE CHANGE}

One of the most critical challenges that the researchers in climate economics have addressed is assessing the environmental intangibles, in other words, non-market values of emissions. Environmental economists have tackled such issues by valuing intangibles and developing policy structures such as environmental taxes, environmental subsidy, and emissions trading to incorporate the non-market prices into the market.

The standard methods to monetize non-market values are categorized into two types. One is the revealed preference method, estimating the values of intangibles through people's actual behaviors. The revealed preference method includes the travel cost method and hedonic approach, which aim to infer the economic value of recreation sites and green spaces. The revealed preference method is also applied in climate economics for evaluating carbon prices (Cullen and Mansur, 2017).

Another method is stated preference approach, based on a survey in which a hypothetical policy that causes a change in environmental condition is shown to respondents. The respondents are asked to directly state their willingness to pay for the policy or indirectly indicate their perceived value for the environment through choosing a preferred policy. An advantage of this method is that it can monetize a change in environmental conditions that have not actually happened. For example, in the context of climate change, MacKerron et al. (2009) have conducted a stated preference survey and investigated the value of a hypothetical project that can offset the emission from airlines. It is also found that willingness to pay (WTP) for reducing emissions varies depending on the type of policies and sociodemographic characteristics (Alberini et al., 2018).

More recent studies have investigated the values of environmental intangibles by focusing on subjective well-being (SWB) indices represented by happiness and life satisfaction. While stated and revealed preference methods are called a decision utility approach because it is based on choice behaviors, assessing environmental goods using SWB is classified as an experienced utility approach because it captures the experienced outcome of a choice. Using ex-post happiness and satisfaction is effective for measuring intangible factors such as mental benefits or costs from an improvement or deterioration of the environment (e.g., Kumagai et al., 2021; Yoo et al., 2021). In the context of climate economics, one strand of research focuses on using SWB for evaluating the damage from natural hazards that will happen more frequently in the future due to climate change (Fernandez et al., 2019). Other studies have shed light on the relationship between emissions and well-being through agriculture and energy consumption and discussed how to address both mitigating climate change and enhancing people's well-being (Lamb and Steinberger, 2017).

Although the impact of various aspects of climate change has been quantified by focusing on individual's choice behavior and experienced satisfaction, it is not yet clear which method can provide the most reliable outcome. Decision utility approach, a conventional one, assumes that an individual predicts which option is most likely to provide the highest utility among a set of alternatives. In other words, decision utility becomes a precise estimate of utility if an individual can accurately predict future experiences from their choice for addressing climate change. However, previous studies have found that people are likely to underestimate the negative aspects of future experiences and suffer more than they expected under the negative influences of choice outcome (Stutzer and Frey, 2008; Frey and Stutzer, 2014). Using an experienced utility approach can address this utility misprediction issues, but few studies have investigated the impacts of climate change on people's experienced utility such as subjective well-being. Further studies are needed to clarify how to correctly grasp and evaluate the impacts of climate change by focusing on both people's choice behavior and satisfaction.

\section{SOCIAL COSTS OF CARBON}

Followed by section Measuring Intangible Consequences of Climate Change, climate economics attempted to monetize the environmental externalities (i.e., carbon emissions), leading to a well-known discussion on the "social costs of carbon" (SCC) representing the economic cost caused by an additional ton of $\mathrm{CO}_{2}$ emissions (or more succinctly carbon) or its equivalent. Estimates of the SCC are a critical component of climate change policy as it can propose the acceptable level of emissions reductions or carbon pricing in policies to minimize emissions at the national or international levels. Policymakers, for example, might use SCC estimates to evaluate the optimal carbon tax or the target rate of emissions reductions under a cap-and-trade regime (Nordhaus, 2014).

Usually, the SCC is calculated using an integrated assessment model (IAM) to simulate a "causal chain" that begins with predicted socioeconomic futures and greenhouse gas emissions. Following the SCC estimation process, the estimated resulting climate change and climate damages for both a reference and a $\mathrm{CO}_{2}$ pulsed emissions trajectory are presented (Rose et al., 2017).

While the estimates of SCC provide critical insights for future climate policy, both have a vital challenge: uncertainty. Numerous previous works are seeking ways to cope with the uncertainty problem by providing methodological toolkits that can address it. Pindyck (2019) proposes an alternative way to calculate "average" SCC which is the ratio of the present value of GDP loss from an extreme outcome to the total emission reduction needed to avert that outcome. Greenstone et al. (2011) suggests incorporating diverse aspects (i.e., technological developments) to the considerations of SCC. Weitzman (2009) mentions that the current SCC calculation needs to consider for the potential catastrophe that can happen due to climate change and not considering it would result in the underestimation of 
SCC. In the same line, some studies propose considering the extreme events in the calculations of SCC. Aurland-Bredesen (2020), Heal (2009), Weitzman (2014), and Millner (2013) shows that considering the extreme disaster events in the SCC calculation process would resolve uncertainty issues. Therefore, it is necessary to better understand the low-problastic, on the economic impact of extreme climatic events. On the other hand, Burke et al. (2016) argue that technological innovations would change SCC estimates while such innovations are not considered in the current SCC calculations. Technological advances can dramatically reduce the costs of climate change and SCC. Therefore, research on SCC requires modeling improvements.

Another challenge is the choice of the discount rate of SCC as climate change is a long-run problem. For several years, debates about the discount rate have been vital to climate change models and policy. Because of the long-delays between abatement expenditures and returns in averted losses, the economic theory of discounting, which was previously an obscure subject in public finance and project research, assumes great prominence in climate economics. The uncertainty for the discount rate can lead to slight variations in assumptions, and it can therefore lead to very different policy recommendations (Stern, 2008; Freeman and Groom, 2016). Arrow et al. (2014) propose resolving the uncertainty of SCC through constructive modeling of discounting and state that discounting is a central issue for current climate policy. For example, discussions on the declining discount rate (DDR) schedule or a constant exponential rate. The concept of DDR is straightforward: if shocks to the consumption discount rate are unpredictable but positively associated, the efficient outcome is a decreasing schedule of discount rates (Gollier and Groom, 2013).

Lots of previous works propose alternative approaches of discounting. Nordhaus (2019) suggests the growth-corrected discount rates, which is defined as the rate of return on capital minus the growth rate of output, which attempts to recognize the damages of climate change is proportional to the size of the economy. Considering regional differences or national economies to estimate SCC is also being conducted across previous works, particularly for the poor and vulnerable (Hallegatte and Rozenberg, 2017; Rao et al., 2017). However, despite such discussions, discount rates remain the major unresolved issue of the SCC. Thus, piling up contributions to the research on discount rates would provide an excellent pathway for SCC-related research.

\section{FUTURE WORKS}

In this paper, we looked into the merits of climate economics, identified the challenges and opportunities. Climate economics helps understanding climate change, and it has drastically

\section{REFERENCES}

Aghion, P., Akcigit, U., Deaton, A., and Roulet, A. (2016). Creative destruction and subjective well-being. Am. Econ. Rev. 106, 3869-3897. doi: $10.1257 /$ aer.20150338 improved through substantial amounts of research support. In this subsection, we propose several branches of possible future research.

First, as the damages from climate change often come with the destruction of physical, human, and natural stocks, taking into account the intangible damages is also necessary (IPCC, 2014). Such a process can consider methods proposed by Benjamin et al. (2012) and Benjamin et al. (2014), which is a unique methodology of measuring individuals' well-being by calculating each fundamental aspect's weight. While there are lots of previous works attempting to measure non-market goods into the utility (Aghion et al., 2016; De Neve et al., 2018; PerezTruglia, 2020), previous works made lots of the same efforts in climate economics as such "non-market" outcomes can include the potential costs of human conflicts (Hsiang et al., 2013) environmental damages (Luechinger, 2009; Ferreira and Moro, 2010) loss in biodiversity (Hoegh-Guldberg and Bruno, 2010) and changes in human health (Watts et al., 2015) due to climate change. Thus, exploring new ways of measuring critical nonmarket outcomes should be necessary.

Second, for the social costs of carbon, which the great attention of previous works attenuate, along with the methodological improvements, a discussion for the right direction for SCC and which SCC to choose needed to be updated. Pizer et al. (2014) show that a regular update of SCC should be conducted with reliable institutions [i.e., governments and the National Academy of Science's National Research Council (NRC)]. Kotchen (2018) mentions the importance of reaching an international consensus of SCC, while it would be challenging because they need developing and using the SCC among sovereign countries is more than just estimating and internalizing an externality. At the same time, Landry (2021) presents that governments can achieve a Pareto optimal allocation through their anthropocentric limit and/or requirement choices. Along with SCC, discussing other types of harmful emissions such as nitrogen (Keeler et al., 2016) is also required as they also contribute to water quality, loss of biodiversity, stratospheric ozone depletion and climate change (Galloway et al., 2008; Townsend and Howarth, 2010). Working on these problems would be needed further.

Overcoming the identified challenges in this paper would help people and policymakers understand the causes, impacts, and solutions for climate change and the implications for the entire global society.

\section{AUTHOR CONTRIBUTIONS}

All authors listed have made a substantial, direct, and intellectual contribution to the work and approved it for publication. survey. Energy Policy. 121, 565-575. doi: 10.1016/j.enpol.2018.07.008

Archer, D., Eby, M., Brovkin, V., Ridgwell, A., Cao, L., Mikolajewicz, U., et al. (2009). Atmospheric lifetime of fossil fuel carbon dioxide. Ann. 
Rev. Earth Planet. Sci. 37, 117-134. doi: 10.1146/annurev.earth.031208.1 00206

Arrow, K. J., Cropper, M. L., Gollier, C., Groom, B., Heal, G. M., Newell, R. G., et al. (2014). Should governments use a declining discount rate in project analysis? Rev. Environ. Econ. Policy 8, 145-163. doi: 10.1093/reep/reu008

Aurland-Bredesen, K. J. (2020). The benefit-cost ratio as a decision criteria when managing catastrophes. Environ. Resour. Econ. 77, 345-363. doi: 10.1007/s10640-020-00498-x

Barnett, J. (2003). Security and climate change. Glob. Environ. Change 13, 7-17. doi: 10.1016/S0959-3780(02)00080-8

Barreca, A., and Schaller, J. (2020). The impact of high ambient temperatures on delivery timing and gestational lengths. Nat.Clim. Change 10, 77-82. doi: 10.1038/s41558-019-0632-4

Benjamin, D. J., Heffetz, O., Kimball, M. S., and Rees-Jones, A. (2012). What do you think would make you happier? what do you think you would choose? Am. Econ. Rev. 102, 2083-2110. doi: 10.1257/aer.102.5.2083

Benjamin, D. J., Heffetz, O., Kimball, M. S., and Szembrot, N. (2014). Beyond happiness and satisfaction: toward well-being indices based on stated preference. Am. Econ. Rev. 104, 2698-2735. doi: 10.1257/aer.104.9.2698

Burke, M., Craxton, M., Kolstad, C. D., Onda, C., Allcott, H., Baker, E., et al. (2016). Opportunities for advances in climate change economics. Science 352, 292-293. doi: 10.1126/science.aad9634

Cullen, J. A., and Mansur, E. T. (2017). Inferring carbon abatement costs in electricity markets: a revealed preference approach using the shale revolution. Am. Econ. J. Econ. Policy 9, 106-133. doi: 10.1257/pol.20150388

Davis, S. J., Caldeira, K., and Matthews, H. D. (2010). Future $\mathrm{CO}_{2}$ emissions and climate change from existing energy infrastructure. Science 329, 1330-1333 doi: 10.1126/science.1188566

De Neve, J. E., Ward, G., De Keulenaer, F., Van Landeghem, B., Kavetsos, G., and Norton, M. I. (2018). The asymmetric experience of positive and negative economic growth: Global evidence using subjective well-being data. Rev. Econ. Stat. 100, 362-375. doi: 10.1162/REST_a_00697

Deschênes, O., Greenstone, M., and Guryan, J. (2009). Climate change and birth weight. Am. Econ. Rev. 99, 211-117. doi: 10.1257/aer.99.2.211

Fernandez, C. J., Stoeckl, N., and Welters, R. (2019). The cost of doing nothing in the face of climate change: a case study, using the life satisfaction approach to value the tangible and intangible costs of flooding in the Philippines. Clim. Dev. 11, 825-838. doi: 10.1080/17565529.2019.1579697

Ferreira, S., and Moro, M. (2010). On the use of subjective well-being data for environmental valuation. Environ. Resourc. Econ. 46, 249-273. doi: 10.1007/s10640-009-9339-8

Freeman, M. C., and Groom, B. (2016). How certain are we about the certaintyequivalent long term social discount rate? J. Environ. Econ. Manag. 79, 152-168. doi: $10.1016 /$ j.jeem.2016.06.004

Frey, B. S., and Stutzer, A. (2014). Economic consequences of mispredicting utility. J. Happ. Stud. 15, 937-956. doi: 10.1007/s10902-013-9457-4

Galloway, J. N., Townsend, A. R., Erisman, J. W., Bekunda, M., Cai, Z., Freney, J. R., et al. (2008). Transformation of the nitrogen cycle: recent trends, questions, and potential solutions. Science 320, 889-892. doi: 10.1126/science.1136674

Gans, J. S. (2012). Innovation and climate change policy. Am. Econ. J. Econ. Policy 4, 125-145. doi: $10.1257 /$ pol.4.4.125

Gollier, C., and Groom, B. (2013). Pricing the planet's future: the economics of discounting in an uncertain world. J. Econ. Liter. 51, 894-897.

Greenstone, M., Kopits, E., and Wolverton, A. (2011). Estimating the Social Cost of Carbon for use in U.S. Federal Rulemakings: A Summary and Interpretation, a Working Paper. MIT center for Energy and Environmental Policy Research.

Hallegatte, S., and Rozenberg, J. (2017). Climate change through a poverty lens. Nat. Clim. Change 7, 250-256. doi: 10.1038/nclimate3253

Heal, G. (2009). Climate economics: a meta-review and some suggestions for future research. Rev. Environ. Econ. Policy. 3, 4-21 doi: 10.1093/reep/ren014

Hoegh-Guldberg, O., and Bruno, J. F. (2010). The impact of climate change on the world's marine ecosystems. Science 328, 1523-1528. doi: $10.1126 /$ science. 1189930

Hsiang, S., and Kopp, R. E. (2018). An economist's guide to climate change science. J. Econ. Perspect. 32, 3-32. doi: 10.1257/jep.32.4.3

Hsiang, S. M., Burke, M., and Miguel, E. (2013). Quantifying the influence of climate on human conflict. Science 341:1235367. doi: 10.1126/science.12 35367
IPCC (2014). "Summary for policymakers," in Climate Change 2014: Impacts, Adaptation, and Vulnerability. Part A: Global and Sectoral Aspects. Contribution of Working Group II to the Fifth Assessment Report of the Intergovernmental Panel on Climate Change, eds C. B. Field, V. R. Barros, D. J. Dokken, K. J. Mach, M. D. Mastrandrea, T. E. Bilir, M. Chatterjee, K. L. Ebi, Y. O. Estrada, R. C. Genova, B. Girma, E. S. Kissel, A. N. Levy, S. MacCracken, P. R. Mastrandrea and L. L. White (Cambridge, UK; New York, NY: Cambridge University Press), $1-32$.

Jones, B. A. (2019). Infant health impacts of freshwater algal blooms: Evidence from an invasive species natural experiment. J. Environ. Econ. Manag. 96, 36-59. doi: 10.1016/j.jeem.2019.05.002

Karakosta, C., Doukas, H., and Psarras, J. (2010). Technology transfer through climate change: setting a sustainable energy pattern. Renew. Sustain. Energy Rev. 14, 1546-1557. doi: 10.1016/j.rser.2010.02.001

Karl, T. R., and Trenberth, K. E. (2003). Modern global climate change. Science 302, 1719-1723. doi: 10.1126/science.1090228

Keeler, B. L., Gourevitch, J. D., Polasky, S., Isbell, F., Tessum, C. W., Hill, J. D., and Marshall, J. D. (2016). The social costs of nitrogen. Sci. Adv. 2:e1600219. doi: 10.1126/sciadv.1600219

Kelly, P. M., and Adger, W. N. (2000). Theory and practice in assessing vulnerability to climate change andFacilitating adaptation. Clim. Change 47, 325-352. doi: 10.1023/A:1005627828199

Kotchen, M. J. (2018). Which social cost of carbon? A theoretical perspective. J. Assoc. Environ. Resour. Econ. 5, 673-694. doi: 10.1086/697241

Kumagai, J., Wakamatsu, M., and Managi, S. (2021). Do commuters adapt to in-vehicle crowding on trains?. Transportation 48, 2357-2399. doi: $10.1007 /$ s11116-020-10133-9

Lamb, W. F., and Steinberger, J. K. (2017). Human well-being and climate change mitigation. Wiley Interdiscip. Rev. Clim. Change 8:e485. doi: 10.1002/wcc.485

Landry, J. R. (2021). Think globally, cap locally, and trade widely: efficient decentralized policy making in the presence of spillovers. J. Assoc. Environ. Resour. Econ. 8, 91-124. doi: 10.1086/711375

Le Quéré, C., Andrew, R. M., Friedlingstein, P., Sitch, S., Hauck, J., Pongratz, J., et al. (2018). Global carbon budget 2018. Earth Syst. Sci. Data 10, 2141-2194.. doi: 10.5194/essd-10-2141-2018

Luechinger, S. (2009). Valuing air quality using the life satisfaction approach. Econ. J. 119, 482-515. doi: 10.1111/j.1468-0297.2008.02241.x

MacKerron, G. J., Egerton, C., Gaskell, C., Parpia, A., and Mourato, S. (2009). Willingness to pay for carbon offset certification and co-benefits among (high-) flying young adults in the UK. Energy Policy 37, 1372-1381. doi: 10.1016/j.enpol.2008.11.023

Millner, A. (2013). On welfare frameworks and catastrophic climate risks. J. Environ. Econ. Manag. 65, 310-325 doi: 10.1016/j.jeem.2012.09.006

Nordhaus, W. (2014). Estimates of the social cost of carbon: concepts and results from the DICE-2013R model and alternative approaches. J. Assoc. Environ. Resour. Econ. 1, 273-312. doi: 10.1086/676035

Nordhaus, W. (2019). Climate change: The ultimate challenge for economics. Am. Econ. Rev. 109, 1991-2014. doi: 10.1257/aer.109.6.1991

Nordhaus, W. D. (1977). Economic growth and climate: the carbon dioxide problem. Am. Econ. Rev. 1977:341-346.

Partridge, M. D., Feng, B., and Rembert, M. (2017). Improving climatechange modeling of US migration. Am. Econ. Rev. 107, 451-455. doi: 10.1257/aer.p20171054

Pecl, G. T., Araújo, M. B., Bell, J. D., Blanchard, J., Bonebrake, T. C., Chen, I. C., et al. (2017). Biodiversity redistribution under climate change: Impacts on ecosystems and human well-being. Science. 355:eaai9214. doi: 10.1126/science.aai9214

Perez-Truglia, R. (2020). The effects of income transparency on well-being: Evidence from a natural experiment. Am. Econ. Rev. 110, 1019-1054. doi: 10.1257/aer.20160256

Pindyck, R. S. (2019). The social cost of carbon revisited. J. Environ. Econ. Manag. 94, 140-160. doi: 10.1016/j.jeem.2019.02.003

Pizer, W., Adler, M., Aldy, J., Anthoff, D., Cropper, M., Gillingham, K., et al. (2014). Using and improving the social cost of carbon. Science 346, 1189-1190. doi: 10.1126/science.1259774

Rao, N. D., van Ruijven, B. J., Riahi, K., and Bosetti, V. (2017). Improving poverty and inequality modelling in climate research. Nat. Clim. Change 7, 857-862. doi: 10.1038/s41558-017-0004-x 
Rose, S. K., Diaz, D. B., and Blanford, G. J. (2017). Understanding the social cost of carbon: a model diagnostic and inter-comparison study. Clim. Change Econ. 8:1750009. doi: 10.1142/S2010007817500099

Spence, A., Poortinga, W., Butler, C., and Pidgeon, N. F. (2011). Perceptions of climate change and willingness to save energy related to flood experience. Nat. Clim. Change 1, 46-49. doi: 10.1038/nclimate1059

Stern, N. (2008). The economics of climate change. Am. Econ. Rev. 98, 1-37. doi: 10.1257/aer.98.2.1

Stutzer, A., and Frey, B. S. (2008). Stress that doesn't pay: the commuting paradox. Scand. J. Econ. 110, 339-366. doi: 10.1111/j.1467-9442.2008.00542.x

Tol, R. S. J. (2009). The economic effects of climate change. J. Econ. Perspect. 23, 29-51. doi: 10.1257/jep.23.2.29

Tol, R. S. J. (2014). Correction and update: the economic effects of climate change. J. Econ. Perspect. 28, 221-226. doi: 10.1257/jep.28.2.221

Townsend, A. R., and Howarth, R. W. (2010). Fixing the global nitrogen problem. Sci. Am. 302, 64-71. doi: 10.1038/scientificamerican02 $10-64$

Watts, N., Adger, W. N., Agnolucci, P., Blackstock, J., Byass, P., Cai, W., et al. (2015). Health and climate change: policy responses to protect public health. Lancet 386, 1861-1914. doi: 10.1016/S0140-6736(15) 60854-6

Weitzman, M. L. (2009). On modeling and interpreting the economics of catastrophic climate change. Rev. Econ. Stat. 91, 1-19. doi: 10.1162/rest. 91.1 .1
Weitzman, M. L. (2014). Fat tails and the social cost of carbon. Am. Econ. Rev. 104, 544-546. doi: 10.1257/aer.104.5.544

Yoo, S., Kawabata, Y., Kumagai, J., and Managi, S. (2021). Insuring wellbeing: psychological adaptation to disasters. MPRA Paper 107632 (Fukuoka: University Library of Munich).

Conflict of Interest: The authors declare that the research was conducted in the absence of any commercial or financial relationships that could be construed as a potential conflict of interest.

Publisher's Note: All claims expressed in this article are solely those of the authors and do not necessarily represent those of their affiliated organizations, or those of the publisher, the editors and the reviewers. Any product that may be evaluated in this article, or claim that may be made by its manufacturer, is not guaranteed or endorsed by the publisher.

Copyright (c) 2021 Yoo, Kumagai and Managi. This is an open-access article distributed under the terms of the Creative Commons Attribution License (CC BY). The use, distribution or reproduction in other forums is permitted, provided the original author(s) and the copyright owner(s) are credited and that the original publication in this journal is cited, in accordance with accepted academic practice. No use, distribution or reproduction is permitted which does not comply with these terms. 